\title{
VITAMIN D SUPPLEMENTATION - IS IT ESSENTIAL FOR LACTATING MOTHERS AND BREAST-FED INFANTS??
}

\author{
Anju Varghese', Jeeji Palocaren², Reshmi Ramachandran³, Celine T. M4 \\ ${ }^{1}$ Associate Professor, Department of Biochemistry, MOSC Medical College, Kolenchery. \\ ${ }^{2}$ Professor \& HOD, Department of Biochemistry, MOSC Medical College, Kolenchery. \\ ${ }^{3}$ Assistant Professor, Department of Community Medicine, MOSC Medical College, Kolenchery. \\ ${ }^{4}$ Associate Professor, Department of Community Medicine, MOSC Medical College, Kolenchery.
}

\begin{abstract}
Vit D deficiency is an upcoming health problem in both developed and developing countries. It is an essential nutrient required for bone metabolism and growth. Need for vitamin D and calcium is higher in embryonic period, infancy, early childhood, puberty, pregnancy, lactation and old age. Vit D supplementation is not included in the present antenatal care and Integrated Management of Neonatal and Childhood Illness (IMNCI) programmes in India.
\end{abstract}

\section{AIM}

This study was done to evaluate the Vit D status of lactating mothers and their exclusively breast fed infants. The study also aims to find the correlation of Vit D with the blood biochemical markers like ALP, PTH, calcium, phosphorus and find the risk factors associated with hypovitaminosis D in infants.

\section{MATERIALS AND METHODS}

Fifty two lactating mothers and their exclusively breastfed infants up to 4 months age were selected and their blood was analysed for Vit D, calcium, phosphorus, ALP and PTH.

\section{RESULTS}

An $86 \%$ of mothers and $87 \%$ of infants showed hypovitaminosis D. There is significant positive correlation between maternal and infant Vit D levels. Vit D of infants showed significant inverse correlation with BMI of mothers and PTH of infants.

\section{CONCLUSION}

Vit D status of exclusively breast fed infants depend on maternal Vit D levels. Infant's bone mineral status is affected by hypovitaminosis D. Therefore, both mothers and infants should be supplemented with Vit D to prevent complications in future.

\section{KEYWORDS}

Alkaline phosphatase (ALP), Body Mass Index (BMI), 25-Hydroxy Vitamin D (25-OH Vit D), Parathyroid Hormone (PTH), Phosphorus (P).

HOW TO CITE THIS ARTICLE: Anju Varghese, Jeeji Palocaren, Reshmi Ramachandran, Celine T. M. "Vitamin D Supplementation is it Essential for Lactating Mothers and Breast-Fed Infants??" Journal of Evolution of Medical and Dental Sciences 2015; Vol. 4, Issue 100, December 14; Page: 16513-16516, D0I: 10.14260/jemds/2015/2456

\section{INTRODUCTION}

Much interest has been focused on Vitamin D and its role in calcium homeostasis in the recent past. Vitamin D or cholecalciferol is a pleiotropic secosteroid formed in the body mainly from the action of Ultraviolet $B$ rays on 7dehydrocholesterol in the skin.[1,2] A small percentage of the vitamin is directly obtained from the diet.

Vitamin D gets hydroxylated in the liver to form calcidiol (25- hydroxy Vit D) and then under the influence of PTH gets hydroxylated in the kidneys to calcitriol (1, 25 Dihydroxy Vit D), which is the active form of Vitamin D. ${ }^{[3]}$ The concentration of calcidiol (25-hydroxy Vit D) estimated in the lab reflects Vitamin D stores in humans. $[4,5]$

Vitamin D plays an important role in cell proliferation, cell cycle control, immune function and most importantly calcium and phosphorus homeostasis.[6] Calcitriol achieves

Financial or Other, Competing Interest: None.

Submission 24-11-2015, Peer Review 25-11-2015,

Acceptance 08-12-2015, Published 12-12-2015.

Corresponding Author:

Dr. Anju Varghese,

Associate Professor,

Department of Biochemistry,

MOSC Medical College,

Kolenchery.

E-mail: anjujoepaulo@gmail.com

DOI:10.14260/jemds/2015/2456 this by three ways: it increases intestinal absorption of calcium, it reduces excretion of calcium (Stimulating reabsorption in the distal renal tubules) and mobilises bone mineral. Without vitamin $\mathrm{D}$, body cannot absorb $\mathrm{Ca}$ and $\mathrm{P}$ adequately and secondary hyperparathyroidism supervenes and blood calcium is maintained by skeletal resorption.

In addition calcitriol is involved in insulin secretion, regulation of parathyroid growth and hormone production, inhibition of production of interleukin by activated $\mathrm{T}$ lymphocytes and immunoglobulins by B lymphocytes.[7,8] For most of these actions it acts like a steroid hormone binding to cytoplasmic receptors and enhancing gene expression. Deficiency of this Vitamin has been linked with increased risk of Type 1 diabetes mellitus, respiratory infection, malignancy, cardiovascular disease along with rickets and osteomalacia.[6]

Many studies have shown a deficiency of Vit D in the general population of our country in spite of the tropical ambience of the country. According to local customs, the mother and the newborn baby are confined indoors with the baby wrapped in swaddling clothes at least for the first few months. In such conditions the exposure to sunlight is minimal to both. Therefore, the only source of Vitamin D for the newborn is mother's milk in the exclusively breastfed infants, which is a poor source of Vitamin D (<25 IU/L to $78 \mathrm{IU} / \mathrm{L}) .{ }^{[9]}$

The infant then depend on the vitamin $\mathrm{D}$, which it has acquired antenatally from the mother through placenta. 
Therefore, the mother's vitamin D levels plays a crucial role in the early development of the child.

This study is done at MOSC Medical College, Kolenchery, which is in a rural area in Kerala. Study is done by the Dept. of Biochemistry on lactating mothers and infants.

\section{AIM OF THE STUDY}

- To evaluate Vit D status of lactating mothers and their full term breast-fed infants up to 4 months age.

- To find the correlation of Vit D with the biochemical markers like ALP, PTH, Ca and Phosphorus.

- To find the risk factors associated with hypovitaminosis D in infants.

\section{MATERIALS AND METHODS}

The study was approved by Institutional Ethics Committee. A written informed consent was obtained from all participants. The study was performed in accordance with the "Ethical guidelines for Biomedical Research on Human Participants, 2006" by the Indian Council of Medical Research and Declaration of Helsinki 2008.

\section{Participants Inclusion Criteria}

Fifty two lactating mothers and their breast fed infants up to 4 months age who came to Paediatric OPD for vaccination were selected for the study. Infant has to be a full term baby in good general health at the time of enrolment.

\section{Exclusion Criteria}

Mothers were not eligible for participation if they had any of the following diagnosis- Pre-existing Type I or II diabetes, hypertension, PTH disease and uncontrolled thyroid disease. Infants receiving Vit D supplementation, infants $<35$ weeks of age with history of $>72$ hrs in Neonatal Intensive Care Unit, any inborn error of metabolism, history of congenital anomalies or a history of consuming more than $10 \%$ of their diet as formula at the time of enrolment were excluded.

\section{METHODS}

Maternal sociodemographic information was collected Mother's height in $\mathrm{cm}$ and weight in $\mathrm{kg}$ was taken to calculate body mass index. Colour of skin was determined through selfassessment. Self-assigned skin colour was fair, medium and dark. Infant gestational age, birth weight, current weight, length and head circumference were also measured according to standard clinical paediatric practise; $2 \mathrm{ml}$ blood sample was drawn from mother and infant to measure circulating VitD (ng/ml), intact PTH (pg/ml), Ca (mg/dl), phosphorus (mg/dl) and ALP (IU/L).

Baseline total circulating 25(OH) D concentration expressed in $\mathrm{ng} / \mathrm{ml}$ in maternal and infant serum sample was used as an indicator of Vit D status and was measured by competitive immunoassay technique.[10] Based on clinical laboratory classifications for both mothers and infants, deficiency was defined as total circulating $25(\mathrm{OH}) \mathrm{D}$ $<20.0 \mathrm{ng} / \mathrm{ml}(<50.0 \mathrm{nmol} / \mathrm{L})$, insufficiency as $20.0-29.9 \mathrm{ng} / \mathrm{ml}$ $(50.0-74.9 \mathrm{nmol} / \mathrm{L})$ and sufficiency as $\geq 30.0 \mathrm{ng} / \mathrm{ml}$ ( $\geq 75.0 \mathrm{nmol} / \mathrm{L})^{[11]}$ Assay of PTH is done by Competitive Immunoassay technique using Vitros immunodiagnostic products and reagents.[12] Assay of Calcium, Phosphorus and ALP is by Colorimetric method using Vitros microslide. ${ }^{[13,14,15]}$

\section{DATA ANALYSIS}

Data were analysed using Microsoft excel. Pearson's correlation coefficient was used for comparing relationship between variables. $\mathrm{P}$ value $\leq 0.05$ is considered statistically significant.

\section{RESULTS}

\begin{tabular}{|c|c|}
\hline Parameters & Number(n=52) \\
\hline Gender female/male & $30 / 22$ \\
\hline Mean age (months) & $2.1 \pm 0.85$ \\
\hline Mean birth weight (kg) & $3.11 \pm 0.39$ \\
\hline Mean present weight (kg) & $4.79 \pm 0.93$ \\
\hline Head circumference $(\mathrm{cm})$ & $38.34 \pm 2.49$ \\
\hline Length $(\mathrm{cm})$ & $55.62 \pm 4.16$ \\
\hline
\end{tabular}

\begin{tabular}{|c|c|}
\hline Parameters & Number(n=52) \\
\hline Mean age (years) & $27.73 \pm 3.40$ \\
\hline Religion Christian & 24 \\
\hline Muslim & 7 \\
\hline Hindu & 21 \\
\hline Complexion Fair & 13 \\
\hline Medium & 28 \\
\hline Dark & 11 \\
\hline Education school(1-12) & 6 \\
\hline Degree & 46 \\
\hline Parity Primi & 26 \\
\hline Others & 26 \\
\hline Socioeconomic status APL & 48 \\
\hline BPL & 4 \\
\hline Mean BMI (kg/m ${ }^{2}$ ) & $26.05 \pm 3.79$ \\
\hline Table 2: Baseline Characteristics of Mother \\
\hline
\end{tabular}

\begin{tabular}{|c|c|}
\hline Mean Vit D mothers (ng/ml) & $21.21 \pm 9.11$ \\
\hline Mean Vit D infants(ng/ml) & $22.71 \pm 7.73$ \\
\hline \multicolumn{2}{|c|}{ Table 3: Vit D level of Mothers and Infants } \\
\hline
\end{tabular}

\begin{tabular}{|c|c|c|}
\hline & Mothers (\%) & Infants (\%) \\
\hline Optimum(30-100 ng/ml) & 19.23 & 13.46 \\
\hline $\begin{array}{c}\text { Insufficiency(20-29 } \\
\mathrm{ng} / \mathrm{ml})\end{array}$ & 32.69 & 46.15 \\
\hline Deficiency(<20 ng/ml) & 48.1 & 40.38 \\
\hline \multicolumn{2}{|c|}{ Table 4: Vit D status of Mothers and Infants } \\
\hline
\end{tabular}

\begin{tabular}{|c|c|c|c|c|}
\hline & Mean & SD & r & P value \\
\cline { 1 - 3 } Vit D(mother) & 21.21 & 8.09 & \multirow{2}{*}{0.473} & \multirow{2}{*}{0.001} \\
\cline { 1 - 2 } Vit D(infant) & 22.71 & 7.73 & & \\
\hline \multicolumn{6}{|l}{ Table 5: Correlation between Vit D Mother and Infant } \\
\hline
\end{tabular}

*There is significant correlation between Vit D mother and infant.

\begin{tabular}{|c|c|c|c|c|}
\hline & Mean & SD & r & P value \\
\hline $\mathrm{Vit} \mathrm{D}(\mathrm{ng} / \mathrm{ml})$ & 21.21 & 8.09 & & \\
\hline $\mathrm{Ca}(\mathrm{mg} / \mathrm{dl})$ & 9.11 & 0.32 & -0.042 & 0.769 \\
\hline $\mathrm{P}(\mathrm{mg} / \mathrm{dl})$ & 4.56 & 0.61 & -0.016 & 0.908 \\
\hline $\mathrm{ALP}(\mathrm{IU} / \mathrm{L})$ & 98.83 & 24.15 & -0.115 & 0.416 \\
\hline $\mathrm{PTH}(\mathrm{pg} / \mathrm{ml})$ & 54.50 & 28.93 & -0.265 & 0.057 \\
\hline Table 6: Correlation between Vit D and Biochemical \\
Parameters in Mothers \\
\hline
\end{tabular}

*No significant correlation between Vit D and biochemical parameters in mothers. 


\begin{tabular}{|c|c|c|c|c|}
\hline & Mean & SD & r & P value \\
\hline $\mathrm{VitD}(\mathrm{ng} / \mathrm{ml}))$ & 22.71 & 7.73 & & \\
\hline $\mathrm{Ca}(\mathrm{mg} / \mathrm{dl})$ & 9.92 & 0.30 & -0.025 & 0.858 \\
\hline $\mathrm{P}(\mathrm{mg} / \mathrm{dl})$ & 6.45 & 0.61 & -0.084 & 0.555 \\
\hline $\mathrm{ALP}(\mathrm{IU} / \mathrm{L})$ & 310.83 & 69.49 & 0.046 & 0.747 \\
\hline $\mathrm{PTH}(\mathrm{pg} / \mathrm{dl})$ & 72.13 & 49.66 & -0.368 & 0.007 \\
\hline \multicolumn{5}{|c|}{ Table 7: Correlation between Vit D and Biochemical } \\
Parameters in Infants
\end{tabular}

*There is significant inverse correlation between Vit D and PTH in infants.

\begin{tabular}{|c|c|c|c|c|}
\hline & Mean & SD & r & P value \\
\hline BMI $\left(\mathrm{kg} / \mathrm{m}^{2}\right)$ & 26.05 & 3.79 & & \\
\hline $\begin{array}{c}\text { Vit D } \\
\text { infant(ng/dl) }\end{array}$ & 22.71 & 7.73 & -0.284 & 0.041 \\
\hline \multicolumn{5}{|c|}{ Table 8: Correlation between BMI of } \\
Mother and Vit D of Infants \\
\hline
\end{tabular}

*There is significant inverse correlation between BMI of mothers and Vit D of infants.

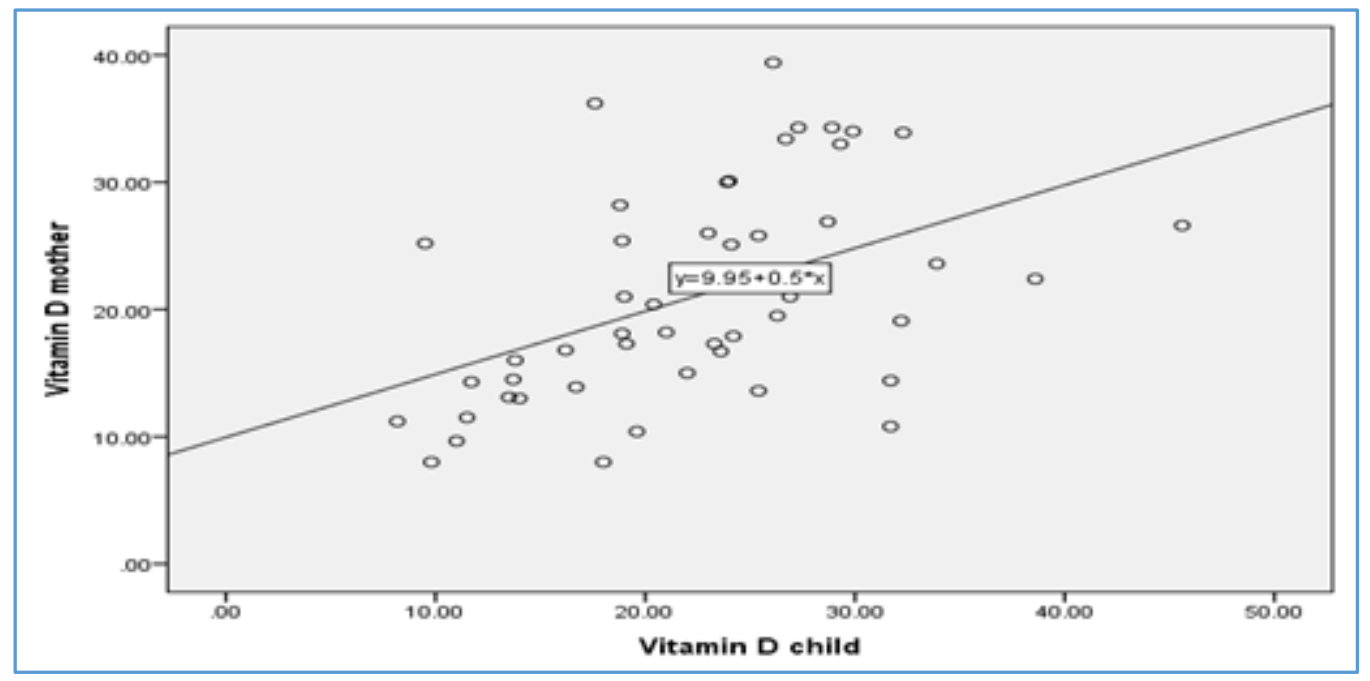

Fig. 1: Scatter diagram showing the relationship between Vit D levels of mother and child

\section{DISCUSSION}

The most important finding in the study is the unexpectedly high prevalence (81\%) of hypovitaminosis D among lactating women. Mean Vit D level of mothers is $21.21 \pm 9.11 \mathrm{ng} / \mathrm{ml}$. Vit D deficiency was biochemically proven in majority of mothers $(48.1 \%)$ and none had exhibited any overt clinical abnormality; $94.1 \%$ belonged to upper socioeconomic status. All the mothers had received regular antenatal care and belonged mostly to Christian (47.1\%), middle income family in suburban area. Nearly all reported of taking calcium supplementation $(500 \mathrm{mg})$ during pregnancy. This was continued postnatally for varying periods of time by majority of mothers. All mothers habitually wore clothing that allowed exposure of head, face and arms and did not practise purdah or use sun screens. Effect of sunlight exposure decreases for individuals with darker skin pigmentation. Melanin decreases cutaneous synthesis of Vit D. It acts as a natural sun screen. ${ }^{16}$

Exactly how much sun exposure is needed for healthy people to maintain normal 25-OH Vit D is not clear. It would of course depend on latitude, season, skin pigmentation and age.[17] It is noted that the restricted exposure to sunlight during postpartum is related to cultural practices in which mothers are restricted from outdoor activities and cared by family members. Although, there is adequate sunshine in Kerala, high temperatures during daytime and humid climate in many areas are the deterrents to follow the advice about sun exposure. At present Vit D supplementation is not a part of antenatal care programmes in India. Vit D deficiency during pregnancy is the origin for a host of future perils for the child, especially its effect on neurodevelopment and immune system. Some of this damage done by maternal Vit D deficiency gets evident after many years.

An $86.5 \%$ of infants were showing hypovitaminosis D. Mean Vit D levels of infant is $22.71 \pm 7.73 \mathrm{ng} / \mathrm{ml}$.
There is a positive correlation between maternal and infant Vit D levels $(\mathrm{P}=0.001)$. One of the potential sources of Vit D synthesis is in the skin from UV B $(290-315 \mathrm{~nm})$ fraction of sunlight. Our traditional practise of oil massage and sunbath to the baby helps in the synthesis of Vit D in the skin. But this has gradually declined due to lifestyle changes. Two hours is the required minimum weekly period of exposure to sunlight for infants if only face is exposed or $30 \mathrm{~min}$ if upper and lower extremities are exposed wearing only a diaper.[18] New born infant born to Vit D replete mother is protected from Vit D deficiency for first few months of life, as 25-OH D crosses the placenta readily and neonatal levels approximate $2 / 3^{\text {rd }}$ of maternal serum concentrations.

Serum 25-OH D has a T1/2 of appropriate 3 weeks, thus providing some protection against $V i t D$ deficiency for a couple of months even if the young infant does not receive Vit D. These infants were exclusively breastfed without supplemental Vit D and none of the mothers were supplemented with Vit D during pregnancy and lactation. Breast milk is low in Vit D ( $<25 \mathrm{IU} / \mathrm{L}$ to $78 \mathrm{IU} / \mathrm{L})$. Therefore, newborn infants who are born Vit D deficient will not improve their Vit D status through exclusive breast feeding.

To increase Vit D content of breast milk requires the mother to consume supplemental Vit D. Vit D supplementation is not a part of antenatal care/Integrated Management of Neonatal and Childhood Illness (IMNCI) programmes in India. In a study by Pittard et al.[19] in preterm and term infants whose mother had normal 25-OH D levels, supplementation with 400-800 IU of Vit D were compared and it was concluded that daily dose of 400 IU was sufficient to achieve normal serum 25-OD D levels.

Maternal obesity is another risk factor for hypovitaminosis D in infants. This is due to inability of fat tissue to sequester Vit $\mathrm{D}$, producing a reduction in 
bioavailability of parent compound for subsequent metabolic activation. [20] Mean BMI of mothers is $26.05 \pm 3.79 \mathrm{~kg} / \mathrm{m}^{2}$. There is an inverse correlation between BMI of mothers and Vit D of infants $(p=0.04)$. Obese women may need larger amounts of vitamin D supplementation to provide their neonates with sufficient levels of vitamin D.

There is also an inverse correlation between Vit $\mathrm{D}$ and PTH in infants $(\mathrm{P}=0.007)$. In hypovitaminosis, PTH levels are found to be elevated. This is a homeostatic mechanism to maintain the serum calcium levels at the expense of bones. One physiological definition of vitamin $\mathrm{D}$ sufficiency is the level of $25(\mathrm{OH}) \mathrm{D}$, at which $\mathrm{PTH}$ production and bone resorption are minimised and intestinal calcium absorption is stabilised without adverse effects. If an infant with hypovitaminosis is not supplemented with Vit D, the infant is likely to develop rickets, which is a more serious health problem.

\section{CONCLUSION}

Hypovitaminosis D is prevalent in lactating mothers and exclusively breast fed infants. Risk factors for hypovitaminosis in infants included maternal hypovitaminosis, maternal obesity, exclusive breast feeding and minimal sun exposure. There are global efforts to promote breast feeding as optimal nutrition in early infancy. Maternal Vit D status and human milk Vit D concentration significantly affect the infant Vit D status and therefore should be of global concern.

In this study, infant's hypovitaminosis is associated with hyperparathyroidism which shows the role of bone in maintaining the normal serum calcium. It is said that "Prevention is better than cure." This is true for Vit D insufficiency and deficiency which are easily preventable. Further studies are needed to document direct evidence of improvement in serum 25(OH) D with calcium and Vit D supplementation in mothers and infants in a large number of subjects in our region.

\section{ACKNOWLEDGEMENTS}

We are thankful to the mothers who participated in the study. Also grateful to medical and non-medical staff of the Department of Paediatrics and Laboratory Staff of Clinical Biochemistry, MOSC Medical College, Kolenchery.

\section{REFERENCES}

1. Lips P, Hosking D, Lippuner K, Norquist JM, Wehren L, Maalouf G, et al. The prevalence of vitamin D inadequacy amongst women with osteoporosis: An international epidemiological investigation. J Intern Med 2006;260:245-54.

2. Collins ED, Norman AW (2001). Vitamin D, in Handbook of Vitamins, eds. Rucker RB, Suttie JW, McCormick DB, Machlin LJ, editors. (New York, NY: Marcel Dekker Inc.), 51-113.

3. Norman, Anthony W. (1998) Sunlight, season, skin pigmentation, vitamin $\mathrm{D}$, and 25-hydroxy vitamin $\mathrm{D}$ : integral components of the vitamin CD endocrine system. Am J Clin Nutr; 67:1108-10.
4. Iqbal SJ. Vitamin D metabolism and the clinical aspects of measuring metabolites. Ann Clin Biochem. 1994;31(Pt 2):109-24.

5. Holick MF. The use and interpretation of assays for vitamin D and its metabolites. J Nutr 1990;120(Suppl 11):1464-9.

6. Holick MF. Mayo clinic proceedings. March 2006 vol 81, Issue 3, 353-373.

7. Michelino Di Rosa, Michele Malaguamera, Ferdinando Nicoletti, Lucia Malaguamera. Vit D3: a helpful immunomodulator. Immunology. 2011 Oct, 134(2);123-139.

8. K Muller, PM Haahr, M Diamant, K Rienech, A Kharazmi, $\mathrm{K}$ Bendtzen. 1,25-dihydroxy Vit D3 inhibits cytokine production by human blood monocytes at post transcriptional level. Cytokine Vol 4, Issue 6, Nov 1992, page 506-512.

9. Wagner CL, Greer Fr; American Academy of Pediatrics Section on Breastfeeding; American Academy of Pediatrics Committee on Nutrition. Prevention of rickets and vitamin deficiency in infants, children and adolscents. Pediatrics 2008;122:1142-1152.

10. Jeffrey KC Lai, et al: Assessing Vitamin D status. Pitfalls for the unwary. Mol. Nutr. Food Res. 2010;54:1-10.

11. Holick MF. Vitamin D deficiency. N Engl J Med 2007;357:266-281.

12. Hawker CD, I Bella FP. Radioimmunoassays for intact and carboxyl-terminal parathyroid hormone; clinical interpretation and diagnostic significance. Ann Clin Lab Sci 1980;10:76-87.

13. Burtis CA, Ashwood ER, eds. Textbook of clinical chemistry. ed 2 Philadelphia: WB Saunders: 1905:1994.

14. Gomori G. A modification of the Colorimetric Phosphorus Determination for use with a photoelectric Colorimeter, J Lab Clin Med 27:955;1942.

15. Tietz NW, Rinker AD, Shaw LM. IFCC Methods for the Measurement of Catalytic Concentration of enzymes. Part 5 IFCC Method for ALP. J Clin Chem Clin Biochem 21:731-748;1983.

16. Chen TC, Chimeh F, Lu Z, Mathieu J, Person KS, Zhang A, Kohn N, Martinello S, Berkowitz R, Holick MF. Factors that influence the cutaneous synthesis and dietary sources of vitamin D. Arch Biochem Biophys. 2007;460:213-217.

17. Holick MF. McCollum Award Lecture, 1994. Vitamin Dnew horizons for the 21st century. Am J Clin Nutr 1994;60:619-30.

18. Specker BL, Valanis B, Hertzberg V, Edwards N, Tsang RC. Sunshine exposure and serum 25-hydroxy Vit D concentrations in exclusively breast-fed infants. J Pediatr 1985;107:372-376.

19. Pittard WB, Geddes KM, Hulsey TC. How much vitamin D for neonates? Am J Dis Child 1991;145:1147-1149.

20. Wortsman J, Matsuoka LY, Chen TC, Lu Z, Holick MF 2000 Decreased bioavailability of vitamin D in obesity. Am J Clin Nutr 72:690-69. 